\title{
Non-thermal dielectric-barrier discharge plasma damages human keratinocytes by inducing oxidative stress
}

\author{
KI CHEON KIM ${ }^{1}$, MEI JING PIAO ${ }^{1}$, SUSARA RUWAN KUMARA MADDUMA HEWAGE ${ }^{1}$, XIA HAN $^{1}$, \\ KYOUNG AH KANG ${ }^{1}$, JIN OH JO ${ }^{2}$, YOUNG SUN MOK ${ }^{2}$, JENNIFER H. SHIN ${ }^{3}$, \\ YEUNSOO PARK ${ }^{4}$, SUK JAE YOO ${ }^{4}$ and JIN WON HYUN ${ }^{1}$ \\ ${ }^{1}$ School of Medicine and Institute for Nuclear Science and Technology, \\ ${ }^{2}$ Department of Chemical and Biological Engineering, Jeju National University, Jeju 63243; \\ ${ }^{3}$ Department of Mechanical Engineering and Graduate School of Medical Science and Engineering, KAIST, Daejeon 34141; \\ ${ }^{4}$ National Fusion Research Institute, Plasma Technology Research Center, Gunsan 54004, Republic of Korea
}

Received July 2, 2015; Accepted October 2, 2015

DOI: 10.3892/ijmm.2015.2405

\begin{abstract}
The aim of this study was to identify the mechanisms through which dielectric-barrier discharge plasma damages human keratinocytes (HaCaT cells) through the induction of oxidative stress. For this purpose, the cells were exposed to surface dielectric-barrier discharge plasma in $70 \%$ oxygen and $30 \%$ argon. We noted that cell viability was decreased following exposure of the cells to plasma in a time-dependent manner, as shown by 3-(4,5-dimethylthiazol-2-yl)-2,5-diphenyltetrazolium bromide assay. The levels of intracellular reactive oxygen species (ROS) were determined using 2',7'-dichlorodihydrofluorescein diacetate and dihydroethidium was used to monitor superoxide anion production. Plasma induced the generation of ROS, including superoxide anions, hydrogen peroxide and hydroxyl radicals. $\mathrm{N}$-acetyl cysteine, which is an antioxidant, prevented the decrease in cell viability caused by exposure to plasma. ROS generated by exposure to plasma resulted in damage to various cellular components, including lipid membrane peroxidation, DNA breaks and protein carbonylation, which was detected by measuring the levels of 8-isoprostane and diphenyl-1-pyrenylphosphine assay, comet assay and protein carbonyl formation. These results suggest that plasma exerts cytotoxic effects by causing oxidative stress-induced damage to cellular components.
\end{abstract}

\section{Introduction}

Plasma, which is an ionized gas, belongs to the fourth state of matter and is composed of charged particles (electrons and

Correspondence to: Professor Jin Won Hyun, School of Medicine and Institute for Nuclear Science and Technology, Jeju National University, 102 Jejudaehakro, Jeju 63243, Republic of Korea

E-mail: jinwonh@jejunu.ac.kr

Key words: plasma, reactive oxygen species, oxidative stress, cell damage ions), electronically excited atoms and molecules, radicals and ultraviolet photons (1). Plasma medicine is a rapidly growing field in research, through which plasma is examined for its possible use in therapeutic applications, such as blood coagulation, tooth whitening, the acceleration of healing of wounds following implant treatment, as well as for the inactivation of bacteria (2-4). In dermatology, atmospheric-pressure plasma is considered promising in the search to heal chronic wounds, as these wounds are contaminated with microorganisms (5). Due to the chemoresistance of chemotheraphy (6) and side-effects of radiotheraphy (7), plasma treatment may be an effective approach to fight cancer, particularly skin carcinoma, if it can induce selective death in cancer tissues. As well as confirming the effectiveness of plasma against a number of physiological disorders, it is also vital to ensure the safe application of plasma models. Keratinocytes are one of the dominant cell types found in the epidermis of human skin, and thus, in the present study, we focused on the effects of non-thermal dielectric-barrier discharge (DBD) plasma on human keratinocytes.

The exact composition of plasma was determined by its temperature and components, as well as the strength and pulse duration of its electric field, as previously described (8). While plasma does not produce a sufficient amount of energetic particles or photons to penetrate cells, reactive oxygen species (ROS) formed by plasma exposure can penetrate and affect cells (9). Excessive amounts of ROS have also been shown to disrupt the homeostatic balance of redox cycling and promote the degradation of proteins, lipids and DNA, leading to oxidative stress $(10,11)$.

It has previously been demonstrated that the effects of exposure to plasma depend on the source of the plasma, such as a plasma jet or needle, and the surface or volume of DBD, the exposure time, and the gas used in the process, such as oxygen, argon or helium (12). Non-thermal DBD plasma was used in the present study, at an atmospheric pressure of $70 \%$ oxygen and $30 \%$ argon, and a high voltage was applied between two electrodes, at least one of which was insulated to prevent current build-up. This method creates electrically safe plasma without causing substantial gas heating. Non-thermal DBD plasma 
generates ROS, such as superoxide anions, hydroxyl radicals, hydrogen peroxide, singlet oxygen and ozone (9).

In the present study, we aimed to elucidate the mechanisms through which plasma damages human keratinocytes (HaCaT cells) by inducing oxidative stress and we thus exposed $\mathrm{HaCaT}$ cells to DBD plasma in $70 \%$ oxygen and $30 \%$ argon.

\section{Materials and methods}

Reagents. 3-(4,5-Dimethylthiazol-2-yl)-2,5-diphenyltetrazolium bromide (MTT), 2',7'-dichlorodihydrofluorescein diacetate (DCF-DA), N-acetyl cysteine (NAC), propidium iodide (PI), Hoechst 33342, dihydroethidium (DHE), superoxide dismutase (SOD), catalase (CAT), and (-)-epigallocatechin gallate (EGCG) were all purchased from Sigma-Aldrich Corp. (St. Louis, MO, USA). Diphenyl-1-pyrenylphosphine (DPPP) was purchased from Molecular Probes (Eugene, OR, USA). All other chemicals and reagents used were of analytical grade.

Cell culture. The human keratinocyte cell line HaCaT was supplied by AmorePacific Corp. (Yongin, Republic of Korea) and maintained at $37^{\circ} \mathrm{C}$ in an incubator in an atmosphere of humidified air $(95 \%)$ and carbon dioxide (5\%). The cells were grown in Dulbecco's modified Eagle's medium supplemented with $10 \%$ fetal calf serum, streptomycin $(100 \mu \mathrm{g} / \mathrm{ml})$ and penicillin $(100 \mathrm{U} / \mathrm{ml})$.

Exposure to plasma. Non-thermal DBD was used as the plasma source (Fig. 1). The electrode system consisted of a polycarbonate board for circuit boards (thickness, $10 \mathrm{~mm}$ ) and had a diameter of $180 \mathrm{~mm}$. The electrodes had an outer diameter of $150 \mathrm{~mm}$ and were separated by a dielectric. The electrode system was installed in a cover plate of a cell culture dish (diameter, $60 \mathrm{~mm}$ ), and the distance to the liquid surface from the electrode was $7 \mathrm{~mm}$. The distances from the cell layer to the electrode and to the liquid surface were 12 and $5 \mathrm{~mm}$, respectively. The DBD plasma functioned in alternating mode. The physical parameters of the plasma were as follows: voltage, $20 \mathrm{kV}$; frequency, $60 \mathrm{~Hz}$; discharge power, $0.9 \mathrm{~W}$. In order to expose the cells to the DBD plasma, the cells were trypsinized and counted to adjust the density at $2 \times 10^{5}$ cells $/ \mathrm{ml}$. For treatment with NAC, $1 \mathrm{mM}$ of NAC was added to the dishes $30 \mathrm{~min}$ prior to exposure to plasma. Subsequently, $11 \mathrm{ml}$ of cell suspension were plated in a 60-mm cell culture dish. Following exposure to DBD plasma, or no exposure to plasma (control), the cell suspensions were transferred to new cell culture dishes or wells to proceed for each experiment.

MTT assay. The cells were plated in 60-mm cell culture dishes in $11 \mathrm{ml}$ of medium at a density of $2 \times 10^{5}$ cells $/ \mathrm{ml}$. Thereafter, the lids were removed from the dishes and cells were exposed to plasma for 1, 2 or $3 \mathrm{~min}$. The cells exposed to plasma were then transferred to a 24 -well plate at a density of $1.0 \times 10^{5}$ cells/well. Twenty-four hours later, $50 \mu \mathrm{l}$ MTT stock solution $(2 \mathrm{mg} / \mathrm{ml})$ were added to each well to yield a total reaction volume of $200 \mu \mathrm{l}$. Following incubation for $4 \mathrm{~h}$, the plate was centrifuged at $800 \mathrm{x} \mathrm{g}$ for $5 \mathrm{~min}$ and the supernatants were aspirated. Formazan crystals in each well were dissolved in $150 \mu \mathrm{l}$ dimethylsulfoxide and the absorbance $\left(\mathrm{A}_{540}\right)$ was measured using a scanning multi-well spectrophotometer (BNR 06298, VERSA max microplate reader; Molecular Devices, Sunnyvale, CA, USA), as previously described (13).

Detection of intracellular ROS. The levels of plasmagenerated intracellular ROS were assessed using DCF-DA, which becomes fluorescent following reaction with hydrogen peroxide $\left(\mathrm{H}_{2} \mathrm{O}_{2}\right)$, hydroxyl radical $\left(\mathrm{OH}^{*}\right)$, superoxide anion radical $\left(\mathrm{O}^{\circ}\right)$, lipid hydroperoxides and $\mathrm{ONOO}^{-}(14,15)$. Cells were pre-treated with $2 \mu \mathrm{g} / \mathrm{ml}$ of SOD, $10 \mu \mathrm{g} / \mathrm{ml}$ of CAT, or $20 \mu \mathrm{M}$ of EGCG for $30 \mathrm{~min}$ and then exposed to plasma. The cells were seeded into a 96 -well plate at a density of $1.0 \times 10^{5}$ cells $/ \mathrm{ml}$ and incubated at $37^{\circ} \mathrm{C}$ for $24 \mathrm{~h}$. DCF-DA $(25 \mu \mathrm{M})$ was added to each well and the cells were maintained for $10 \mathrm{~min}$ in the dark. Fluorescent $2^{\prime}, 7^{\prime}$-dichlorofluorescein (DCF) generated by ROS was detected using a flow cytometer (Becton-Dickinson, Mountain View, CA, USA) or a PerkinElmer LS-5B spectrofluorometer (PerkinElmer, Waltham, MA, USA). The generation of intercellular ROS (\%) detected using a spectrofluorometer was calculated as follows: the generation of intercellular ROS $(\%)=$ (the optical density of the plasma-exposed group - the optical density of group not exposed to plasma)/the optical density of group not exposed to plasma x100. For the image analysis of intracellular ROS, the plasma-exposed cells were seeded onto a 4-well chamber slide at a density of $2 \times 10^{5}$ cells $/ \mathrm{ml}$ and incubated for $24 \mathrm{~h}$. DCF-DA $(100 \mu \mathrm{M})$ was then added to each well and the cells were incubated for an additional $30 \mathrm{~min}$ at $37^{\circ} \mathrm{C}$. After washing with phosphate-buffered saline, the DCF-stained cells were mounted on a chamber slide with mounting medium (Dako, Carpinteria, CA, USA). Images were obtained using a confocal microscope and Laser Scanning Microscope 5 PASCAL software (Carl Zeiss, Jena, Germany).

Detection of intracellular superoxide anion. DHE, by virtue of its ability to freely permeate the cell membrane, is extensively used to monitor superoxide production of which $>90 \%$ is produced in the mitochondria (16). DHE was oxidized to fluorescent ethidium by superoxide anion and this fluorescence was detected at $610 \mathrm{~nm}$ (excitation at $535 \mathrm{~nm}$ ). The levels of superoxide anion in the plasma-exposed cells were assessed using a flow cytometer and a confocal microscope (2J00018, IX81; Olympus, Tokyo, Japan) after staining the cells with $5 \mu \mathrm{M}$ DHE for $20 \mathrm{~min}$.

Colony formation. The plasma-exposed cells were plated in $100-\mathrm{mm}$ cell culture dishes (400 cells/dish) and incubated for 2 weeks at $37^{\circ} \mathrm{C}$ in an incubator. The medium was changed every 3 days. The colonies were stained using the Diff-Quick staining kit (Sysmex, Kobe, Japan) according to the manufacturer's instructions. The colony forming units (CFU) were considered visible. The images of visualized CFU were taken and counted using image $\mathbf{J}$ software.

Flow cytometric analysis for the detection of cell viability. Cell viability was examined using a flow cytometer following PI staining. The cells were incubated for 30 min with PI, and the cell population (living and dead cells) was assessed using a flow cytometer (Becton-Dickinson). Living and dead cells were assessed based on the dot plots generated using the BD CellQuest Pro software program (Becton-Dickinson). 


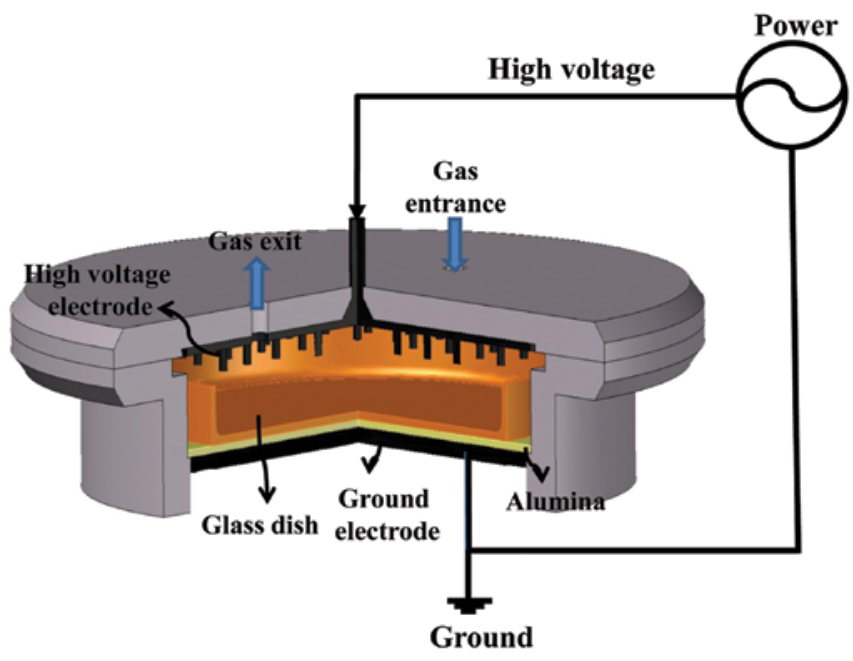

Figure 1. Schematic diagram of the dielectric-barrier discharge (DBD) plasma system.

Lipid peroxidation assay. Lipid peroxidation was assayed by determining the level of 8 -isoprostane $(17,18)$ in the culture medium using a commercial enzyme immunoassay (Cayman Chemical, Ann Arbor, MI, USA) according to the manufacturer's instructions. Lipid peroxidation was also estimated using the fluorescent probe, DPPP, as previously described (19). The cells were incubated with $5 \mu \mathrm{M}$ DPPP for $15 \mathrm{~min}$ in the dark and were then exposed to the plasma. Images of DPPP fluorescence were analyzed using a Zeiss Axiovert 200 inverted microscope at an excitation wavelength of $351 \mathrm{~nm}$ and an emission wavelength of $380 \mathrm{~nm}$.

Single cell gel electrophoresis (comet assay). A comet assay was performed to determine the degree of oxidative DNA damage, as previously described (20). The cell suspension was mixed with $75 \mu \mathrm{l} 0.5 \%$ low melting agarose (LMA) at $39^{\circ} \mathrm{C}$ and then spread onto a fully frosted microscope slide pre-coated with $200 \mu 1 \%$ normal melting agarose. After solidification of the agarose, the slide was covered with another $75 \mu 10.5 \%$ LMA and immersed in lysis solution $(2.5 \mathrm{M} \mathrm{NaCl}, 100 \mathrm{mM} \mathrm{Na}$-EDTA, $10 \mathrm{mM}$ Tris, $1 \%$ Triton X-100 and 10\% dimethylsulfoxide, $\mathrm{pH} 10$ ) for $1 \mathrm{~h}$ at $4^{\circ} \mathrm{C}$. The slides were then placed in a gel electrophoresis apparatus containing $300 \mathrm{mM} \mathrm{NaOH}$ and $10 \mathrm{mM}$ Na-EDTA ( $\mathrm{pH} \mathrm{13)} \mathrm{for} 40 \mathrm{~min}$ to allow for the unwinding of DNA and alkali-labile damage sites. Subsequently, an electrical field $(300 \mathrm{~mA}, 25 \mathrm{~V})$ was applied for $20 \mathrm{~min}$ at $4^{\circ} \mathrm{C}$ to draw the negatively charged DNA toward the anode. Following electrophoresis, the slides were washed 3 times for $5 \mathrm{~min}$ at $4{ }^{\circ} \mathrm{C}$ in neutralizing buffer (0.4 M Tris, $\mathrm{pH} 7.5)$ and stained with $75 \mu \mathrm{l}$ PI $(20 \mu \mathrm{g} / \mathrm{ml})$. The slides were observed under a fluorescence microscope (5E03674, BX60; Olympus) and using an image analyzer (Komet 5.5; Kinetic Imaging, Liverpool, UK). The percentage of total fluorescence in the tail and the length of the tail were recorded in 50 cells/slide.

Protein carbonyl formation. The amount of protein carbonyl formation was determined using an Oxiselect ${ }^{\mathrm{TM}}$ Protein Carbonyl ELISA kit purchased from Cell Biolabs (San Diego, CA, USA) according to the manufacturer's instructions.

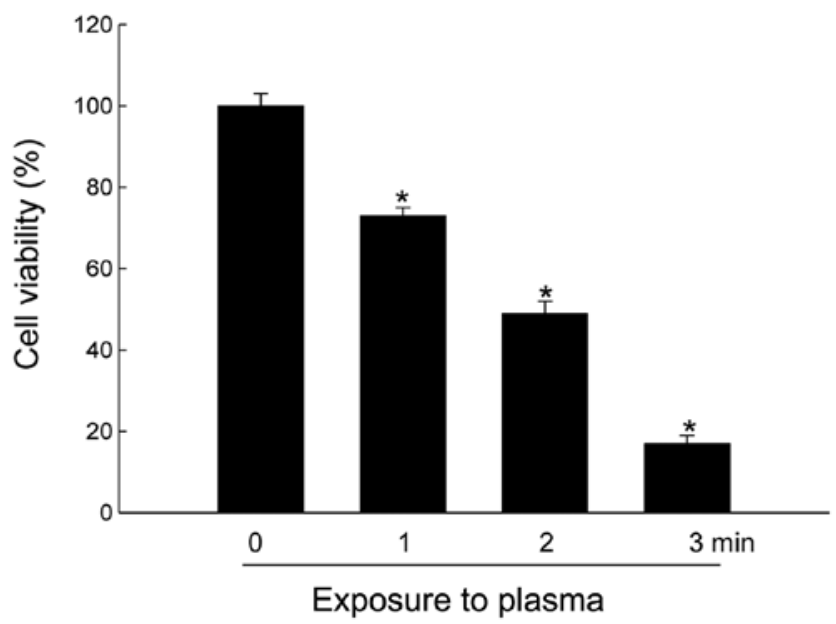

Figure 2. Viability of HaCaT cells following exposure to dielectric-barrier discharge (DBD) plasma. Cells were exposed to plasma for 1, 2 and $3 \mathrm{~min}$. Following incubation for a further $24 \mathrm{~h}$, cell viability was determined by MTT assay. " $\mathrm{p}<0.05$ indicates a significant difference from the control (no exposure to plasma).

In brief, $12 \mathrm{~h}$ following exposure to plasma, the cells were harvested and the pellets were washed with PBS prior to lysis with protein carbonyl lysis buffer. Supernatants were obtained and quantified prior to loading onto the specific protein carbonyl assay plate and incubated overnight at $4^{\circ} \mathrm{C}$. The proteins in the plate were then precipitated by the addition of DNPH working solution. Blocking solution was then added to facilitate proper binding of the anti-DNP antibody. Subsequently, HRP-conjugated secondary antibody was added and substrate solution was used to develop the color. The absorbance values were measured using a spectrophotometer (BNR 06298, VERSA max microplate reader; Molecular Devices) at $450 \mathrm{~nm}$. BSA standards were used to calculate the protein carbonyl content.

Statistical analysis. All measurements were taken in triplicate and all values are expressed as the means \pm standard error of the means. The results were subjected to an analysis of variance followed by Tukey's test. A p-value $<0.05$ was considered to indicate a statistically significant difference.

\section{Results}

Non-thermal DBD plasma induces cytotoxicity. Non-thermal plasma DBD in $70 \%$ oxygen and $30 \%$ argon at a voltage of $20 \mathrm{kV}$ exerted cytotoxic effects on the HaCaT cells in a time-dependent manner, with $50 \%$ growth inhibition $\left(\mathrm{IC}_{50}\right)$ observed within 2 min of exposure (Fig. 2). This was thus selected as the optimal plasma exposure time for use in further experiments.

Exposure to plasma induces ROS generation. ROS generation has been reported to be an important mechanism through which plasma exerts toxic effects $(9,21)$. Thus, in the present study, in order to examine the potential role of oxidative stress induced by plasma, the levels of intracellular ROS were measured. The increased level of ROS in response to 
A

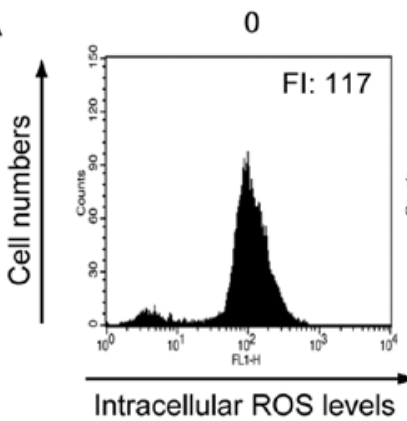

ntracellular ROS levels
3

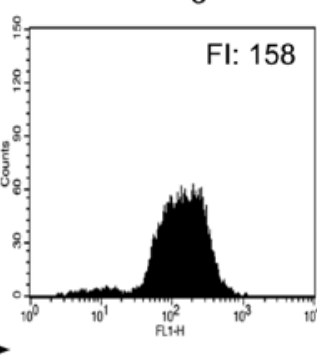

6

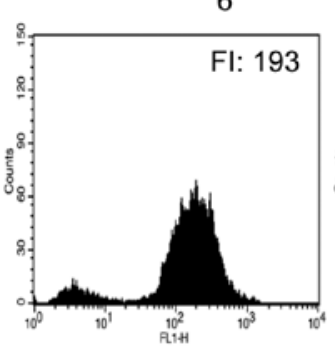

$24 \mathrm{~h}$

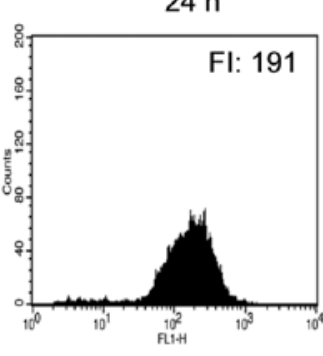

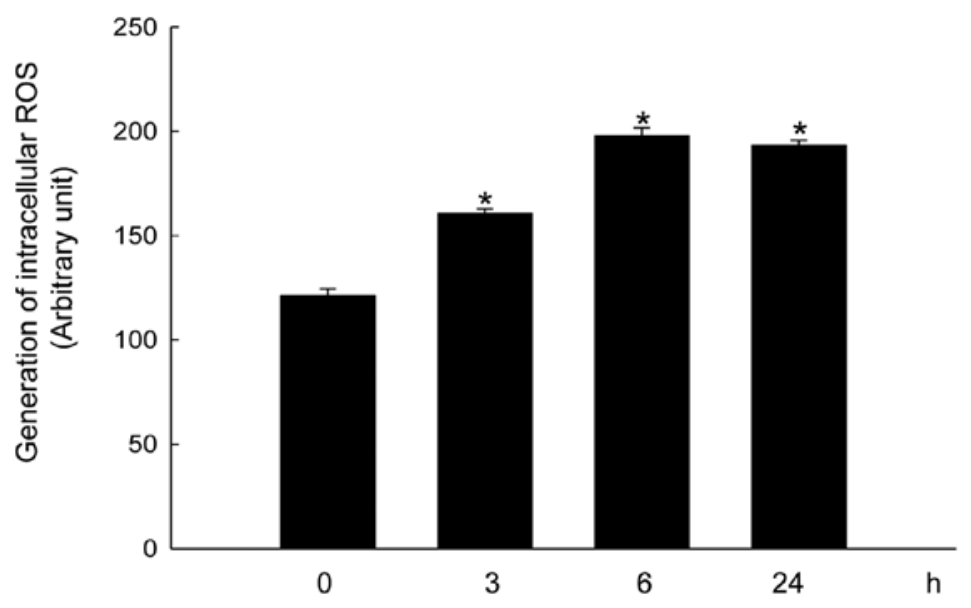

B

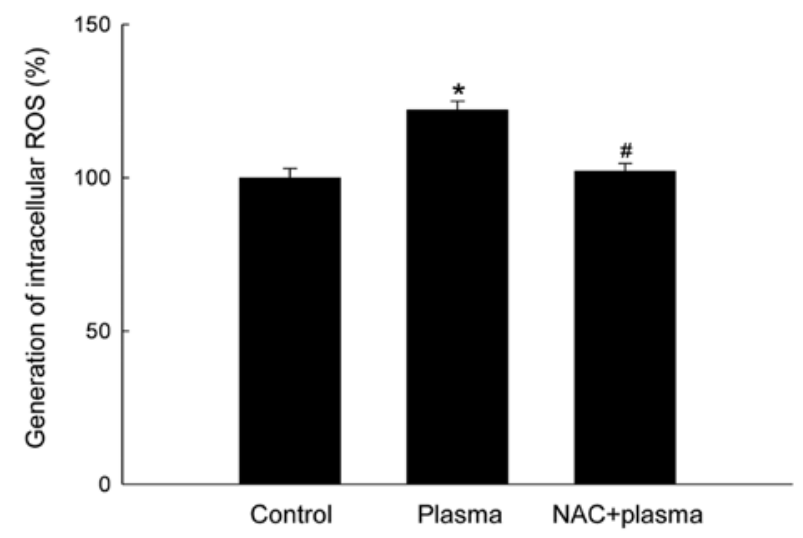

C

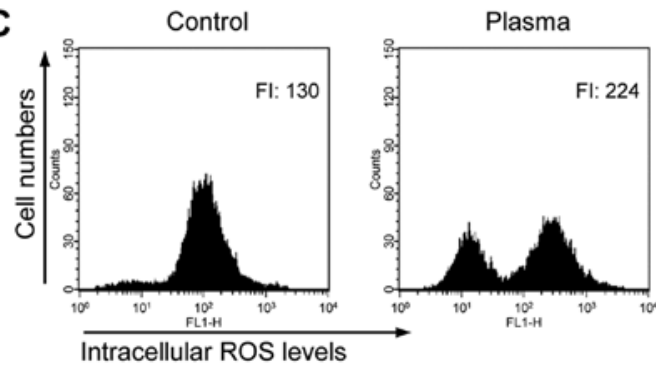

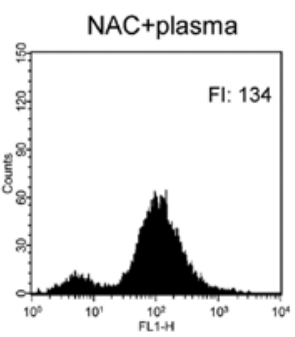

Figure 3. Effects of generation of intracellular reactive oxygen species (ROS) in response to exposure to dielectric-barrier discharge (DBD) plasma on HaCaT cells. (A) Intracellular ROS levels at 0,3,6 and $24 \mathrm{~h}$ following exposure to plasma for 2 min were detected by flow cytometry after DCF-DA treatment. FI indicates the fluorescence intensity of DCF. ${ }^{\mathrm{p}}<0.05$ indicates a significant difference compared to the control. Intracellular ROS levels at $24 \mathrm{~h}$ following exposure to plasma for 2 min in N-acetyl cysteine (NAC)-untreated or NAC-pre-treated cells were detected by (B) spectrofluorometry and (C) flow cytometry after DCF-DA staining. ${ }^{*} \mathrm{p}<0.05$ indicates a significant difference from the control and ${ }^{*} \mathrm{p}<0.05$ significant difference from the plasma-exposed cells.

exposure to plasma for 2 min was significantly maintained for $24 \mathrm{~h}$ (Fig. 3A). NAC, a well-known antioxidant, suppressed the plasma-induced ROS generation detected using a spectrofluo- rometer at $24 \mathrm{~h}$ following exposure to plasma (Fig. 3B). This pattern was confirmed by our flow cytometry data. Our results revealed that the fluorescence intensity at $24 \mathrm{~h}$ was 224 in the 
D
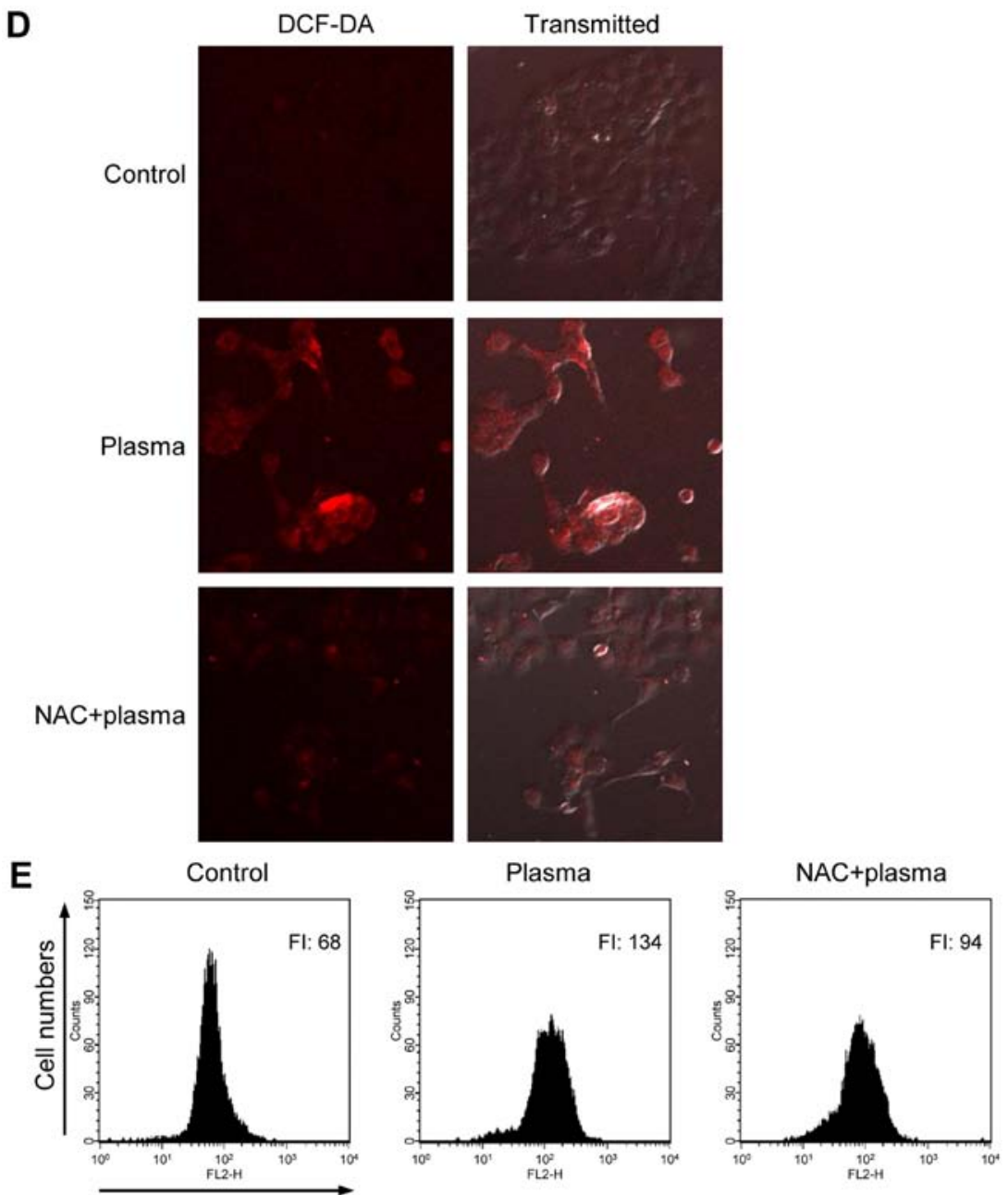

Superoxide anion levels

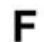

DHE
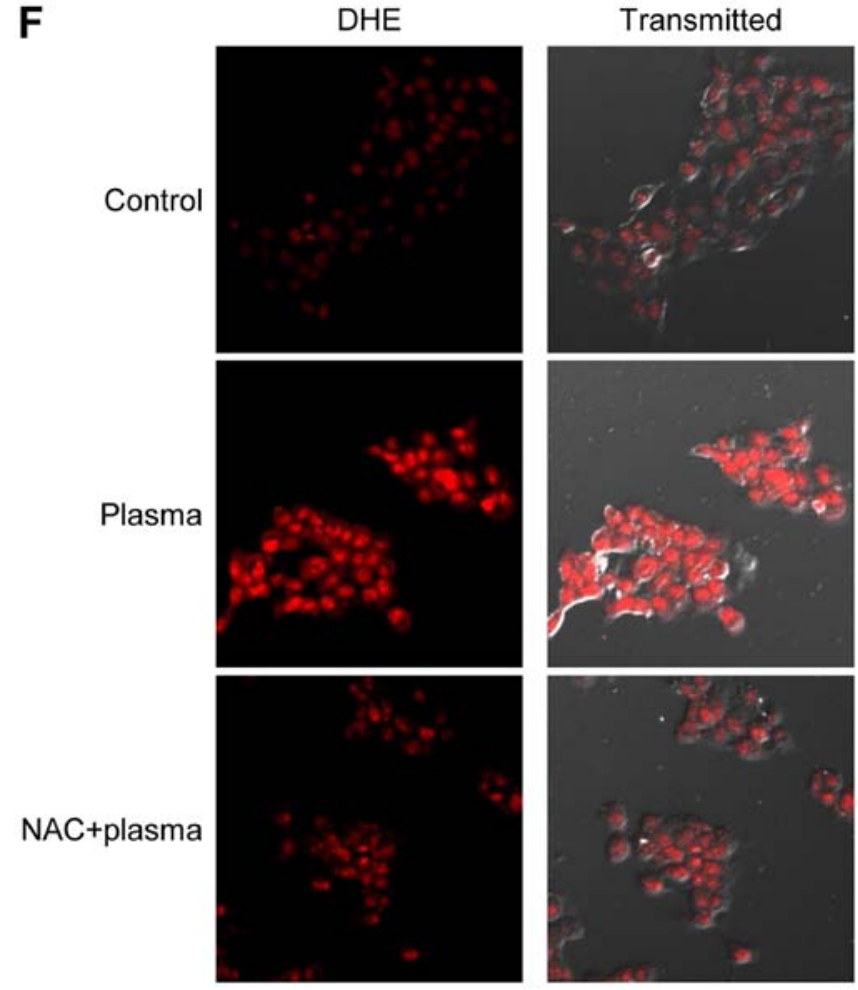

Figure 3. Continued. (D) Confocal images illustrate the increase in DCF fluorescence intensity (red) produced by ROS in plasma-exposed cells, in comparison with that in control cells. Generation of intracellular superoxide anion was detected by (E) flow cytometry and (F) confocal microscopy after dihydroethidium (DHE) staining. Confocal images illustrate the increase in DHE fluorescence intensity (red) produced by the superoxide anion in plasma-exposed cells, in comparison with that in the control cells. 

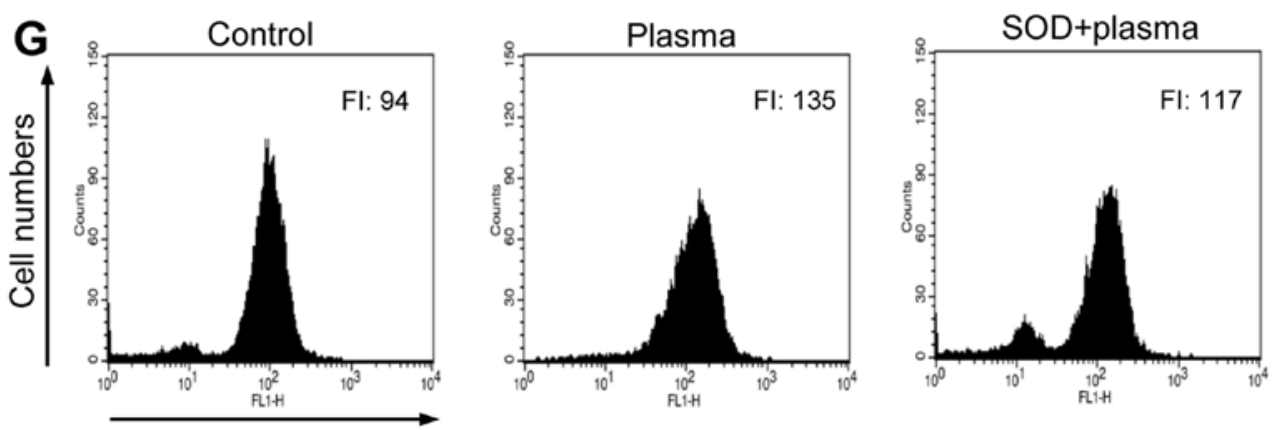

Intracellular ROS levels
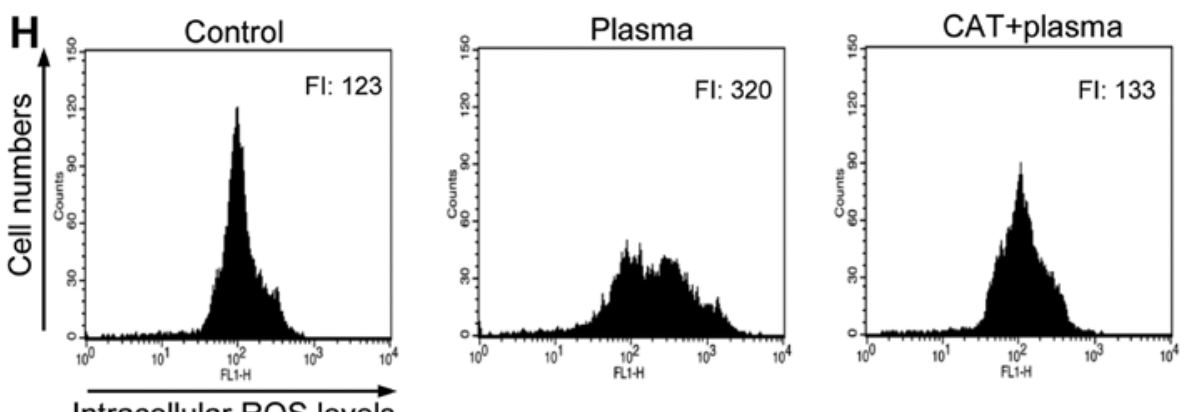

Intracellular ROS levels
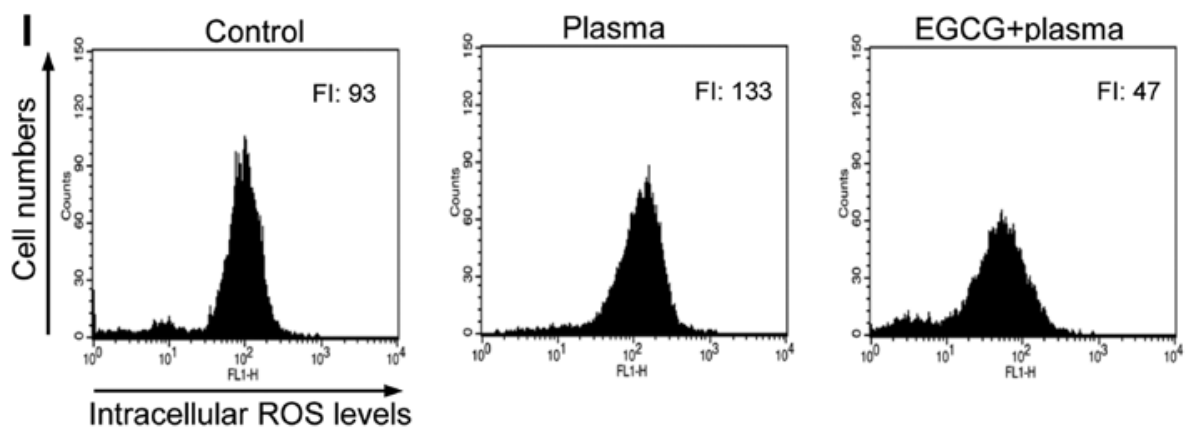

Figure 3. Continued. Cells were pre-treated with (G) $2 \mu \mathrm{g} / \mathrm{ml}$ superoxide dismutase (SOD), (H) $10 \mu \mathrm{g} / \mathrm{ml}$ catalase (CAT), or (I) $20 \mu \mathrm{M}$ (-)-epigallocatechin gallate (EGCG) for $30 \mathrm{~min}$ and then exposed to plasma. Intracellular ROS levels at $24 \mathrm{~h}$ following exposure to plasma were detected by flow cytometry after DCF-DA treatment.

plasma-exposed cells compared to 130 in the control cells; however, treatment with NAC (fluorescence intensity, 134) attenuated the increase in ROS levels induced by exposure to plasma (Fig. 3C). Furthermore, confocal microscopy demonstrated that red fluorescence intensity, which is indicative of ROS, was higher in the plasma-exposed cells than in the control cells; however, this increase was suppressed by NAC (Fig. 3D). In addition, the levels of intracellular superoxide anion were detected using DHE, a specific probe for this type of ROS. Flow cytometric data revealed that the fluorescence intensity at $24 \mathrm{~h}$ was 134 in plasma-exposed cells compared with 68 in the control cells; however, treatment with NAC decreased the levels of superoxide anion to 94 following exposure to plasma (Fig. 3E). The data of the confocal microscopy images were also consistent with the flow cytometric data (Fig. 3F). Furthermore, SOD, a scavenger of superoxide anion (Fig. 3G), CAT, a scavenger of hydrogen peroxide (Fig. 3H) and EGCG, a scavenger of hydroxyl radicals (Fig. 3I), suppressed ROS generated in response to exposure to plasma. These results suggest that exposure of cells to plasma results in the production of ROS, including superoxide anions, hydrogen peroxide, and hydroxyl radicals.
Plasma-induced cytotoxicity is mediated by oxidative stress. To determine whether ROS are involved in plasma-induced cytotoxicity, cell viability was measured following treatment of the cells with NAC prior to exposure to plasma. The results of MTT assay revealed that pre-treatment with NAC prevented the decrease in cell viability induced by exposure to plasma (Fig. 4A). These data are consistent with our calculations of the numbers of colonies (Fig. 4B) and PI-stained cells (dead cells) (Fig. 4C).

Oxidative stress induced by exposure to plasma damages cellular components. The plasma-exposed cells demonstrated increased levels of lipid peroxidation, as measured by the level of 8-isoprostane (Fig. 5A) and by the microscopic observation of groups stained with DPPP, a specific fluorescent probe that detects lipid peroxidation in cell membranes (Fig. 5B). The tail length and percentage of DNA in the tails was higher in plasma-exposed cells than in the control cells (Fig. 5C). The protein carbonyl content was higher in the plasma-exposed cells than in the control cells (Fig. 5D). These results suggest that exposure to plasma damages cellular components through oxidative stress. 
A

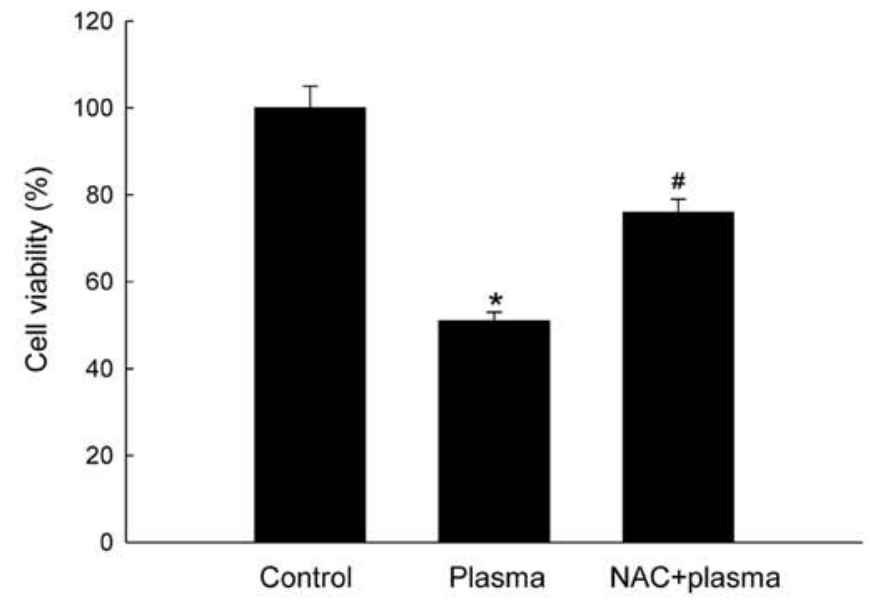

B Control

Plasma

$\mathrm{NAC}+$ plasma
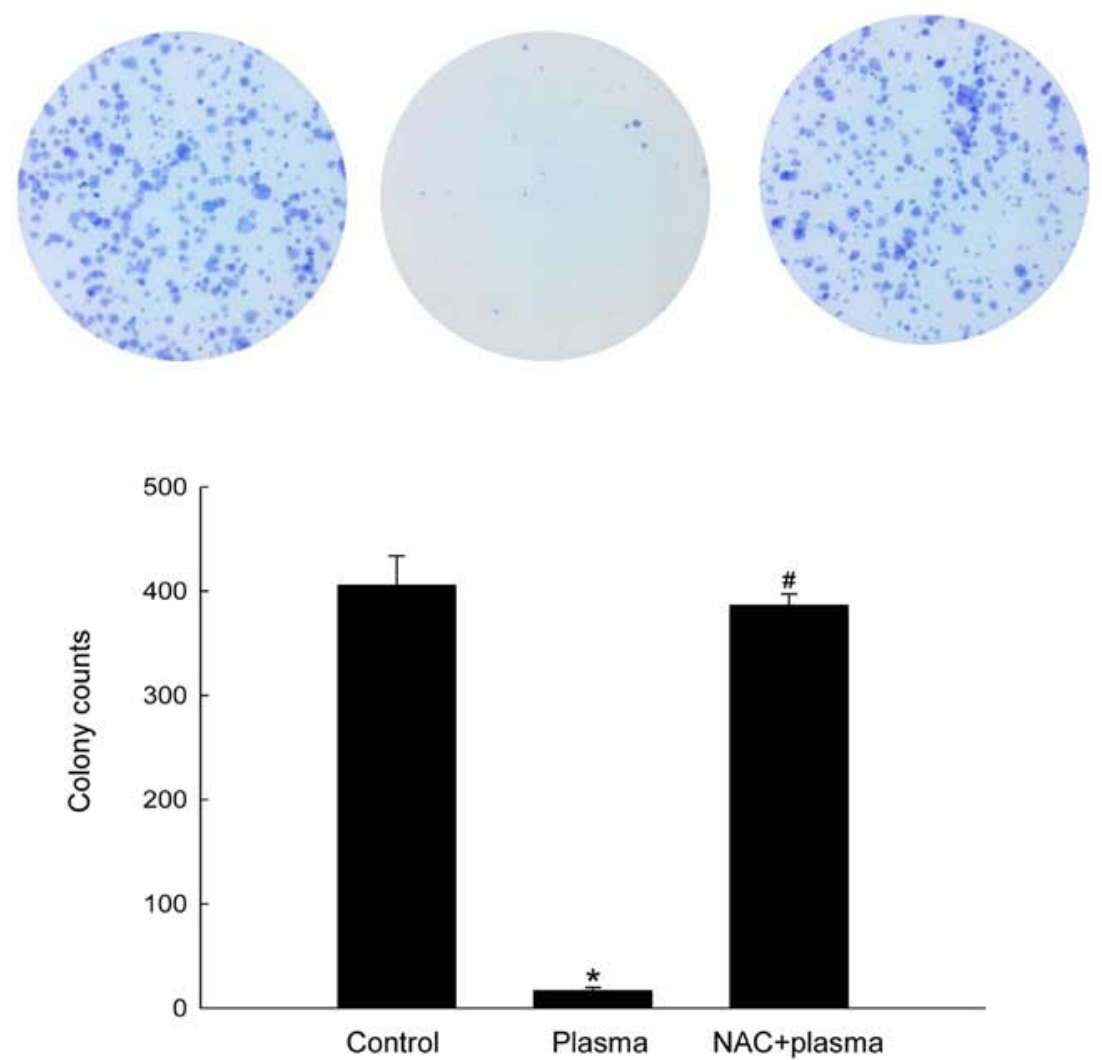

\section{C}
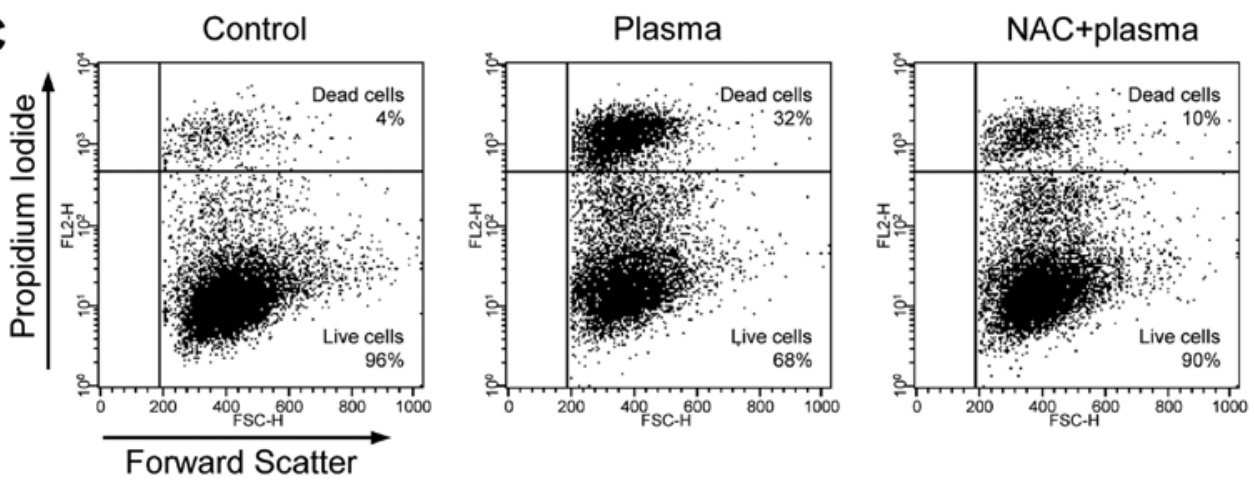

Figure 4. Effect of the antioxidant, N-acetyl cysteine (NAC), on plasma-induced cytotoxicity. Cells were pretreated with $1 \mathrm{mM}$ NAC for 30 min and exposed to plasma for 2 min. (A) Following incubation for $24 \mathrm{~h}$, cell viability was assessed by MTT assay. (B) For colony formation assays, cells were cultured for 2 weeks following exposure to plasma for $2 \mathrm{~min}$. Colonies of $>400$ cells were counted. ${ }^{*} \mathrm{p}<0.05$ indicates a significant difference from the control, and ${ }^{\#} \mathrm{p}<0.05$ a significant difference from the plasma-exposed cells. (C) PI-stained cells were examined by flow cytometry. The populations of dead cells and live cells are represented as the dot blots. 

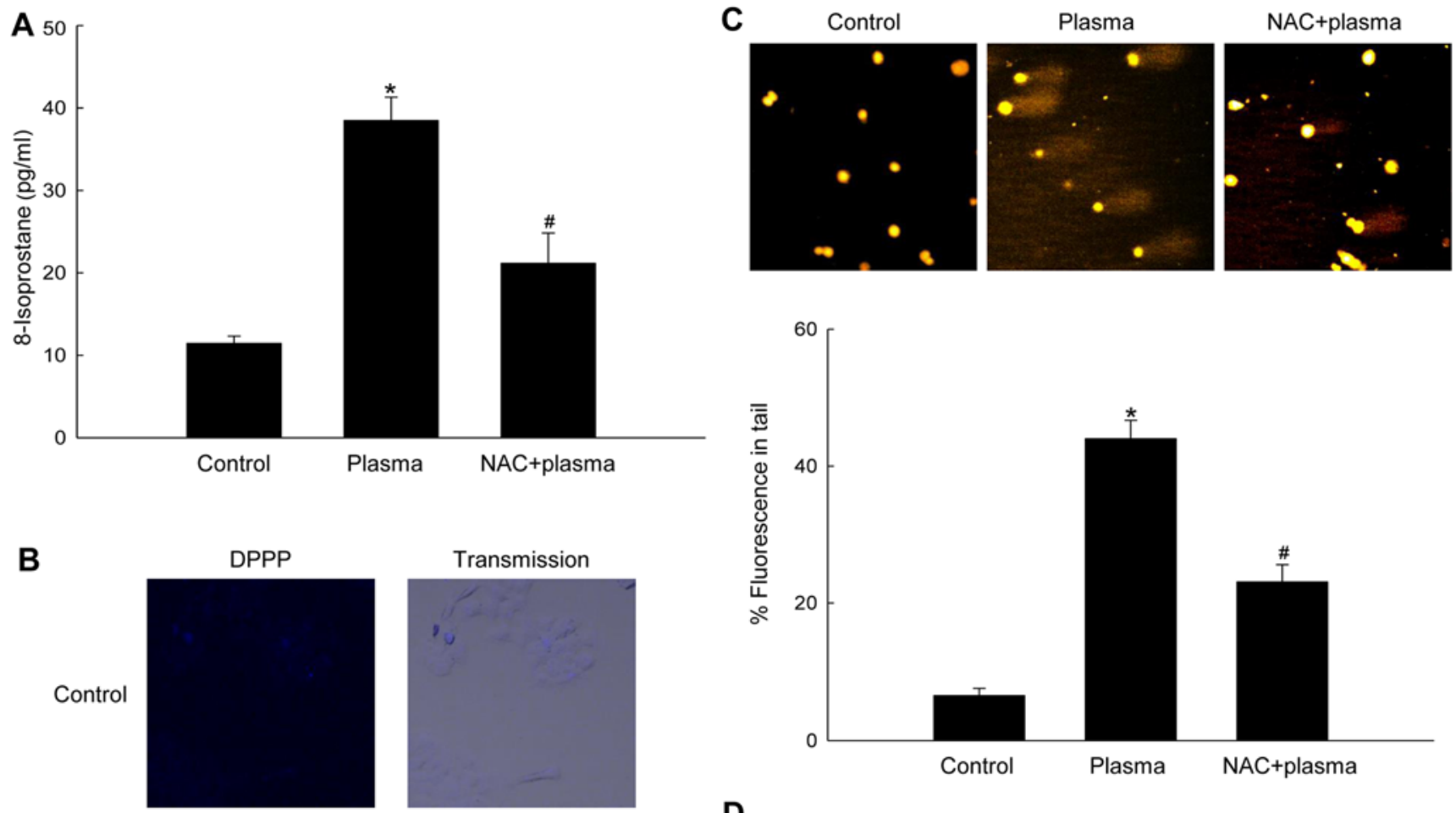

D

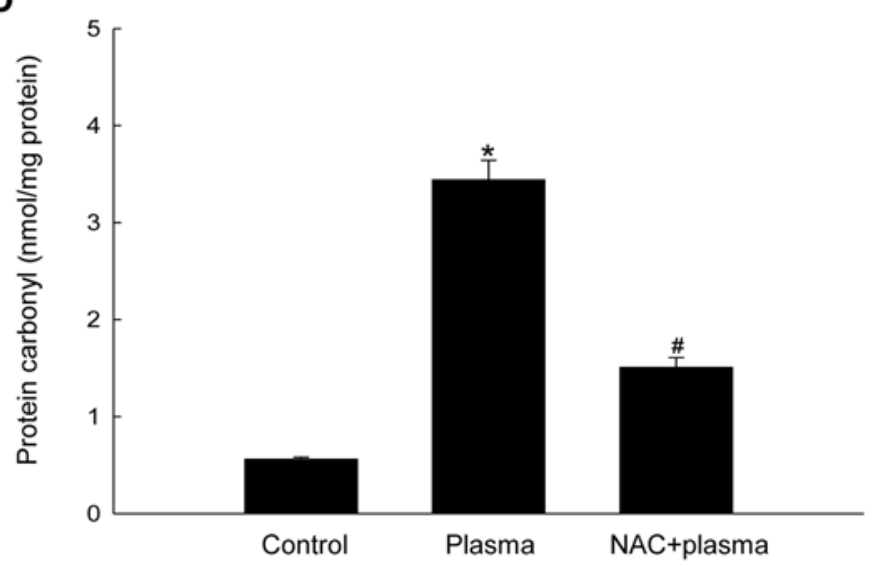

Figure 5. Oxidative stress-induced damage to cellular components following exposure to plasma. Cells were pre-treated with $1 \mathrm{mM} \mathrm{N}$-acetyl cysteine (NAC) for $30 \mathrm{~min}$ and exposed to plasma for $2 \mathrm{~min}$. Lipid peroxidation was assayed by (A) measuring the levels of 8-isoprostane and (B) using confocal microscopy after diphenyl-1-pyrenylphosphine (DPPP) staining. (C) DNA damage was assessed by using the alkaline comet assay. The representative images of comet tails and percentage of cellular fluorescence within comet tails are presented. (D) ${ }^{*} \mathrm{p}<0.05$ indicates a significant difference from the control and ${ }^{\#} \mathrm{p}<0.05$ significant difference from the plasma-exposed cells.

\section{Discussion}

This study provides evidence for a molecular mechanism through which plasma induces cell damage via the generation of ROS and the induction of cytotoxicity. Consistent with previous reports which have noted that plasma provokes oxidative stress $(22,23)$, our results demonstrated that exposure to plasma induced the generation of superoxide anions, hydrogen peroxide and hydroxyl radicals in $\mathrm{HaCaT}$ human skin keratinocytes. Moreover, ROS generation in the plasma-exposed cells was decreased by pre-treatment with NAC. Kalghatgi et al (9) reported that non-thermal DBD plasma generates ROS, such as superoxide anions, hydrogen peroxide, hydroxyl radicals, single oxygen and ozone (3). ROS induced by hydrogen peroxide, gamma-rays and ultraviolet $\mathrm{B}$ radiation cause oxidative damage to cellular components and cell death via mitochondrialmediated apoptosis in $\mathrm{HaCaT}$ cells, according to our recent studies (24-26).

It is known that ROS attack cellular components, including DNA, lipids and proteins, and cause various types of oxidative damage $(27,28)$. Thus, in the present study, using a comet assay, which examines DNA strand breaks and alkali-labile sites, we observed that exposure to non-thermal DBD plasma increased the DNA tail length. As previously demonstrated, organic peroxide generated from non-thermal DBD plasma induces the generation of p-histone H2A.X, a histone derivative that is phosphorylated in response to DNA damage, in an ataxiatelangiectasia mutated-and Rad3-related (ATR)-dependent and 
ataxia-telangiectasia mutated (ATM)-independent manner (9). In the present study, we detected only the presence of ROS in the DBD plasma-exposed cells by using DCF-DA, and DHE staining dye, not the ROS origin. In terms of the origins of ROS generation, ROS are generated by cytochrome P450, the mitochondrial electron transport chain, the nicotinamide adenine dinucleotide phosphate oxidase, the xanthine oxidase and the uncoupling of nitric oxide synthase in the cell (29). In future studies, we aim to investigate which ROS generating systems are stimulated by exposure to DBD plasma, thus leading to an increase in ROS levels.

In the present study, exposure to plasma was shown to cause cell membrane lipid peroxidation using the 8-isoprostane and DPPP assays. 8-Isoprostane is a member of the non-enzymatic eicosanoid family, a family which is produced by the random oxidation of tissue or cellular phospholipids. DPPP reacts with lipid hydroperoxides produced by ROS to generate the fluorescent product, DPPP oxide, and the corresponding hydroxide. Joshi et al reported that non-thermal DBD plasma induces membrane lipid peroxidation mainly via single oxygen and hydrogen peroxide species in Escherichia coli, resulting in the inactivation or the death of bacteria (23). In addition, oxidative damage to amino acid residues, particularly arginine, lysine, proline and threonine, results in the formation of carbonyl derivatives and can compromise cellular integrity, protein function and proteasome activity $(30,31)$. The protein carbonyl content of cells was increased significantly by plasma exposure. DNA damage, lipid peroxidation and protein carbonylation resulted from plasma-induced ROS generation, leading to cell death. Previous studies have shown that plasma triggers ROS-mediated cell death via apoptosis or endoplasmic reticulum stress (32-35). However, the mechanisms underlying ROS-mediated cell death induced by DBD plasma in our system remain to be evaluated. Furthermore, this study demonstrated the importance of regulating the plasma conditions in order to achieve the selective induction of cell death in cancer cells, which may prove to be useful for future studies.

\section{Acknowledgements}

This study was supported by the R\&D Program of Plasma Advanced Technology for Agriculture and Food (Plasma Farming) through the National Fusion Research Institute of Korea (NFRI) funded by the Korean government.

\section{References}

1. Goree J: Charging of particles in a plasma. Plasma Sources Sci Technol 3: 400-406, 1994.

2. Rhodes NP, Wilson DJ and Williams RL: The effect of gas plasma modification on platelet and contact phase activation processes. Biomaterials 28: 4561-4570, 2007.

3. Blumhagen A, Singh P, Mustapha A, Chen M, Wang Y and Yu Q: Plasma deactivation of oral bacteria seeded on hydroxyapatite disks as tooth enamel analogue. Am J Dent 27: 84-90, 2014.

4. Nam SH, Lee HJ, Hong JW and Kim GC: Efficacy of nonthermal atmospheric pressure plasma for tooth bleaching. ScientificWorldJournal 2015: 581731, 2015.

5. Hill KE, Davies CE, Wilson MJ, Stephens P, Harding KG and Thomas DW: Molecular analysis of the microflora in chronic venous leg ulceration. J Med Microbiol 52: 365-369, 2003.

6. Rushworth SA, Zaitseva L, Murray MY, Shah NM, Bowles KM and MacEwan DJ: The high Nrf2 expression in human acute myeloid leukemia is driven by NF- $\mathrm{kB}$ and underlies its chemoresistance. Blood 120: 5188-5198, 2012
7. Yip D, Allen R, Ashton C and Jain S: Radiation-induced ulceration of the stomach secondary to hepatic embolization with radioactive yttrium microspheres in the treatment of metastatic colon cancer. J Gastroenterol Hepatol 19: 347-349, 2004.

8. Munir ZA, Anselmi-Tamburini U and Ohyanagi M: The effect of electric field and pressure on the synthesis and consolidation of materials: a review of the spark plasma sintering method. J Mater Sci 41: 763-777, 2006.

9. Kalghatgi S, Kelly CM, Cerchar E, Torabi B, Alekseev O, Fridman A, Friedman G and Azizkhan-Clifford J: Effects of nonthermal plasma on mammalian cells. PLoS One 6: e16270, 2011.

10. Halliwell B: Reactive oxygen species in living systems: source, biochemistry, and role in human disease. Am J Med 91: 14S-22S, 1991.

11. Apel K and Hirt H: Reactive oxygen species: metabolism, oxidative stress, and signal transduction. Annu Rev Plant Biol 55: 373-399, 2004

12. Haertel B, Straßenburg S, Oehmigen K, Wende K, von Woedtke T and Lindequist U: Differential influence of components resulting from atmospheric-pressure plasma on integrin expression of human HaCaT keratinocytes. BioMed Res Int 2013: 761451, 2013.

13. Carmichael J, DeGraff WG, Gazdar AF, Minna JD and Mitchell JB: Evaluation of a tetrazolium-based semiautomated colorimetric assay: assessment of chemosensitivity testing. Cancer Res 47: 936-942, 1987.

14. Bass DA, Parce JW, Dechatelet LR, Szejda P, Seeds MC and Thomas M: Flow cytometric studies of oxidative product formation by neutrophils: a graded response to membrane stimulation. J Immunol 130: 1910-1917, 1983.

15. Rosenkranz AR, Schmaldienst S, Stuhlmeier KM, Chen W, Knapp W and Zlabinger GJ: A microplate assay for the detection of oxidative products using 2',7'-dichlorofluorescin-diacetate. J Immunol Methods 156: 39-45, 1992.

16. Budd SL, Castilho RF and Nicholls DG: Mitochondrial membrane potential and hydroethidine-monitored superoxide generation in cultured cerebellar granule cells. FEBS Lett 415: 21-24, 1997.

17. Beauchamp MC, Letendre E and Renier G: Macrophage lipoprotein lipase expression is increased in patients with heterozygous familial hypercholesterolemia. J Lipid Res 43: 215-222, 2002.

18. Manzer R, Wang J, Nishina K, McConville G and Mason RJ: Alveolar epithelial cells secrete chemokines in response to IL-1beta and lipopolysaccharide but not to ozone. Am J Respir Cell Mol Biol 34: 158-166, 2006

19. Okimotoa Y, Watanabea A, Nikia E, Yamashitab T and Noguchia N: A novel fluorescent probe diphenyl-1-pyrenylphosphine to follow lipid peroxidation in cell membranes. FEBS Lett 474: 137-140, 2000.

20. Singh NP: Microgels for estimation of DNA strand breaks, DNA protein crosslinks and apoptosis. Mutat Res 455: 111-127, 2000.

21. Vandamme M, Robert E, Lerondel S, Sarron V, Ries D, Dozias S, Sobilo J, Gosset D, Kieda C, Legrain B, et al: ROS implication in a new antitumor strategy based on non-thermal plasma. Int $\mathrm{J}$ Cancer 130: 2185-2194, 2012

22. Arjunan KP and Clyne AM: Non-thermal dielectric barrier discharge plasma induces angiogenesis through reactive oxygen species. Conf Proc IEEE Eng Med Biol Soc 2011: 2447-2450, 2011.

23. Joshi SG, Cooper M, Yost A, Paff M, Ercan UK, Fridman G, Friedman G, Fridman A and Brooks AD: Nonthermal dielectricbarrier discharge plasma-induced inactivation involves oxidative DNA damage and membrane lipid peroxidation in Escherichia coli. Antimicrob Agents Chemother 55: 1053-1062, 2011.

24. Zheng J, Piao MJ, Keum YS, Kim HS and Hyun JW: Fucoxanthin protects cultured human keratinocytes against oxidative stress by blocking free radicals and inhibiting apoptosis. Biomol Ther (Seoul) 21: 270-276, 2013.

25. Piao MJ, Kim KC, Chae S, Keum YS, Kim HS and Hyun JW: Protective effect of fisetin (3,7,3', '-tetrahydroxyflavone) against gamma-irradiation-induced oxidative stress and cell damage. Biomol Ther (Seoul) 21: 210-215, 2013.

26. Cha JW, Piao MJ, Kim KC, Yao CW, Zheng J, Kim SM, Hyun CL, Ahn YS and Hyun JW: The polyphenol chlorogenic acid attenuates UVB-mediated oxidative stress in human HaCaT katinocytes. Biomol Ther (Seoul) 22: 136-142, 2014.

27. Inoue $S$ and Kawanishi S: Hydroxyl radical production and human DNA damage induced by ferric nitrilotriacetate and hydrogen peroxide. Cancer Res 47: 6522-6527, 1987.

28. Burton GJ and Jauniaux E: Oxidative stress. Best Pract Res Clin Obstet Gynaecol 25: 287-299, 2011.

29. Holmström KM and Finkel T: Cellular mechanisms and physiological consequences of redox-dependent signalling. Nat Rev Mol Cell Biol 15: 411-421, 2014. 
30. Stadtman ER and Berlett BS: Fenton chemistry. Amino acid oxidation. J Biol Chem 266: 17201-17211, 1991.

31. Dalle-Donne I, Aldini G, Carini M, Colombo R, Rossi R and Milzani A: Protein carbonylation, cellular dysfunction, and disease progression. J Cell Mol Med 10: 389-406, 2006.

32. Ishaq M, Kumar S, Varinli H, Han ZJ, Rider AE, Evans MD, Murphy AB and Ostrikov K: Atmospheric gas plasma-induced ROS production activates TNF-ASK1 pathway for the induction of melanoma cancer cell apoptosis. Mol Biol Cell 25: 1523-1531, 2014.

33. Zhao S, Xiong Z, Mao X, Meng D, Lei Q, Li Y, Deng P, Chen M, Tu M, Lu X, et al: Atmospheric pressure room temperature plasma jets facilitate oxidative and nitrative stress and lead to endoplasmic reticulum stress dependent apoptosis in HepG2 cells. PLoS One 8: e73665, 2013.
34. Ahn HJ, Kim KI, Kim G, Moon E, Yang SS and Lee JS: Atmospheric-pressure plasma jet induces apoptosis involving mitochondria via generation of free radicals. PLoS One 6: e28154, 2011.

35. Kang SU, Cho JH, Chang JW, Shin YS, Kim KI, Park JK, Yang SS, Lee JS, Moon E, Lee K and Kim CH: Nonthermal plasma induces head and neck cancer cell death: the potential involvement of mitogen-activated protein kinase-dependent mitochondrial reactive oxygen species. Cell Death Dis 5: e1056, 2014. 